\title{
EDITORIAL
}

\section{Biomechanical effects of interspinous process devices using a hybrid testing protocol}

\author{
Paul M. Arnold, MD, ${ }^{1}$ and Elizabeth A. Friis, $\mathrm{PhD}^{2}$ \\ 1Department of Neurosurgery, University of Kansas Medical Center, Kansas City; and 'Department of Mechanical Engineering, \\ University of Kansas, Lawrence, Kansas
}

$\mathrm{T}$ HE use of lumbar interspinous process (ISP) devices for the treatment of symptomatic lumbar stenosis has dramatically increased in the past decade, ${ }^{1,2}$ very likely because of the increased number of elderly patients in the population. Such patients tend to have several comorbidities, which increase the risk of lumbar laminectomy; thus, a less invasive surgical procedure was required to manage this common problem. Interspinous process devices are appealing because they can often be inserted with less risk than a standard laminectomy. ${ }^{6}$

In 2005, the FDA approved the use of ISP devices for the treatment of neurogenic claudication. Currently, several devices are on the market in Europe and the United States, and the most frequently used device is the X-Stop (Medtronic Inc.). The goal of an ISP device is to prevent extension and functionally increase the area of the spinal canal and neuroforamina at the level at which the device is placed. The procedure often takes less than 30 minutes, and minimal dissection of the posterior elements is required..$^{9,12}$

Knowledge of the biomechanics of these devices is useful to the practicing surgeon. Several in vitro and in vivo studies have assessed range of motion (ROM), intradiscal pressure (IDP), facet loading, and effects on adjacent segments. ${ }^{4}$ The study by Erbulut et al. ${ }^{3}$ is a finite-element (FE) analysis in which the authors looked at several biomechanical effects of an X-Stop-like device on the implanted and adjacent lumbar segments. The authors used a hybrid testing model that applied the moment levels necessary to achieve displacements identical to those of the intact specimen. ${ }^{10,11}$ While this approach may better represent the in vivo mechanics of motion, this particular test protocol has been studied infrequently. ${ }^{7}$

The authors found that the device tested would be predicted to decrease ROM, facet load, and IDP at the index level, although this was only tested in extension. Notably, they found that the facet load at the index level would be nearly 0 in extension in the implanted condition. They also noted that both IDP and facet loads would increase at the adjacent levels.

These study findings are helpful for surgeons contemplating the use of ISP devices in patients with lumbar stenosis. The findings are similar to those in several other studies, with a notable exception: previous studies predicted that IDP at the adjacent levels would decrease after the ISP device was placed, but in fact it increased in the FE model. ${ }^{8}$ The reason for this difference from cadaveric studies was thought to be a result of the hybrid loading applied. The current study also showed maximum stresses at the site of implantation and compared these locations to spinous process fractures that have been associated with ISP device placement. ${ }^{14,15}$

There are several flaws in the design of the current study that must be taken into consideration. The FE model developed by the authors used data from a healthy 35-year-old male, not a 70-year-old patient who would be more likely to receive the device. Though tissue property data from other FE studies were used, the spinous processes (where most of the stress is transferred after instrumentation) were probably more robust in the younger patient. It was not stated what age range the material properties represented, and viscoelastic properties were not simulated. Validation of the model was done through comparison of motion data from previous studies, which is not necessarily valid for a different geometric specimen. ${ }^{5}$ In addition, no validation or comparison was made for IDPs in the model, yet those parameters were measured and compared between conditions. While the study pointed out some limitations of cadaveric mechanical testing, it does not fully explore the many limitations of FE analysis. Moreover, implantation of the device was only simulated at 1 level, L3-4. It is not clear why this level was chosen despite the fact that 
L4-5 is the more commonly implanted level. Other levels and implant designs could have been incorporated into their analysis. The authors discussed extensively how the hybrid loading approach influenced study results, yet no direct comparisons were made in their model. Comparison of a fixed moment versus hybrid loading technique could have yielded interesting comparisons to reinforce the authors' position. ${ }^{16}$

The device tested was purported to resemble X-Stop. However, the rendering accompanying the paper has several design features that differ from the X-Stop, including the ability to have some effect on lateral bending and rotation. There was no explanation for why this particular device alone was studied. In addition, the authors chose only to test extension in their ROM analysis, whereas other FE studies routinely test flexion, lateral bending, and axial rotation, even though, as the authors note, the ISP device has little if any effect on those parameters. ${ }^{13}$

Biomechanical testing and FE analysis play valuable roles in the assessment and creation of spinal implants and devices. To a certain extent, they can often model and predict in the laboratory how hardware will perform in humans, without the need for more elaborate or invasive investigation. However, when evaluating data, and perhaps when extrapolating the findings, close attention must be paid to the design and methodology of each individual study.

http://thejns.org/doi/abs/10.3171/2015.1.SPINE141277

\section{References}

1. Anderson PA, Tribus CB, Kitchel SH. Treatment of neurogenic claudication by interspinous decompression: application of the X STOP device in patients with lumbar degenerative spondylolisthesis. J Neurosurg Spine 4:463-471, 2006

2. Barbagallo GM, Olindo G, Corbino L, Albanese V: Analysis of complications in patients treated with the X-Stop Interspinous Process Decompression System: proposal for a novel anatomic scoring system for patient selection and review of the literature. Neurosurgery 65:111-119, 2009

3. Erbulut DU, Zafarparandeh I, Hassan CR, Lazoglu I, Ozer AF: Determination of the biomechanical effect of an interspinous process device on implanted and adjacent lumbar spinal segments using a hybrid testing protocol: a finiteelement study. J Neurosurg Spine [epub ahead of print May 1, 2015. DOI: 10.3171/2014.12.SPINE14419]

4. Gazzeri R, Galarza M, Alfieri A: Controversies about interspinous process devices in the treatment of degenerative lumbar spine diseases: past, present, and future. Biomed Res Int 2014:975052, 2014

5. Jones AC, Wilcox RK: Finite element analysis of the spine: towards a framework of verification, validation and sensitivity analysis. Med Eng Phys 30:1287-1304, 2008

6. Kondrashov DG, Hannibal M, Hsu KY, Zucherman JF: Interspinous process decompression with the X-STOP device for lumbar spinal stenosis: a 4-year follow-up study. J Spinal Disord Tech 19:323-327, 2006

7. Lafage V, Gangnet N, Sénégas J, Lavaste F, Skalli W: New interspinous implant evaluation using an in vitro biomechanical study combined with a finite-element analysis. Spine (Phila Pa 1976) 32:1706-1713, 2007

8. Lindsey DP, Swanson KE, Fuchs P, Hsu KY, Zucherman JF, Yerby SA: The effects of an interspinous implant on the kinematics of the instrumented and adjacent levels in the lumbar spine. Spine (Phila Pa 1976) 28:2192-2197, 2003
9. Nandakumar A, Clark NA, Smith FW, Wardlaw D: Two-year results of X-stop interspinous implant for the treatment of lumbar spinal stenosis: a prospective study. J Spinal Disord Tech 26:1-7, 2013

10. Panjabi M, Malcolmson G, Teng E, Tominaga Y, Henderson $\mathrm{G}$, Serhan H: Hybrid testing of lumbar CHARITE discs versus fusions. Spine (Phila Pa 1976) 32:959-967, 2007

11. Panjabi MM. Hybrid multidirectional test method to evaluate spinal adjacent-level effects. Clin Biomech (Bristol, Avon) 22:257-265, 2007

12. Puzzilli F, Gazzeri R, Galarza M, Neroni M, Panagiotopoulos K, Bolognini A, et al: Interspinous spacer decompression (X-STOP) for lumbar spinal stenosis and degenerative disk disease: a multicenter study with a minimum 3-year followup. Clin Neurol Neurosurg 124:166-174, 2014

13. Siddiqui M, Karadimas E, Nicol M, Smith FW, Wardlaw D: Effects of X-STOP device on sagittal lumbar spine kinematics in spinal stenosis. J Spinal Disord Tech 19:328-333, 2006

14. Swanson KE, Lindsey DP, Hsu KY, Zucherman JF, Yerby SA: The effects of an interspinous implant on intervertebral disc pressures. Spine (Phila Pa 1976) 28:26-32, 2003

15. Wilke HJ, Heuer F, Schmidt H: Prospective design delineation and subsequent in vitro evaluation of a new posterior dynamic stabilization system. Spine (Phila Pa 1976) 34:255-261, 2009

16. Wiseman CM, Lindsey DP, Fredrick AD, Yerby SA: The effect of an interspinous process implant on facet loading during extension. Spine (Phila Pa 1976) 30:903-907, 2005

\section{Response}

\section{Deniz U. Erbulut, PhD, ${ }^{1,2}$ Iman Zafarparandeh, MSc, ${ }^{1}$ and Ali F. Ozer, MD2}

Departments of ${ }^{1}$ Mechanical Engineering and ${ }^{2}$ Neurosurgery, Koc University, Istanbul, Turkey

We thank Drs. Arnold and Friis for their valuable comments in the editorial.

The goal of our study was to investigate the effect of an ISP device on the biomechanical behavior of treated and adjacent segments of the lumbar spine. An FE method was used in our study because it can help to understand internal biomechanical parameters, such as stresses and strains. ${ }^{6}$ A hybrid, rather than a flexible, protocol was selected to better understand the behavior of adjacent segments. Compared to a flexible protocol, the hybrid protocol is more anatomically relevant, especially when the response of adjacent levels is of interest. ${ }^{2}$

In our study we focused on the design concept of the ISP devices, which are mainly designed to prevent motion in extension. Therefore, we did not compare different ISP devices. We used a design similar to X-Stop, as that device has been documented most extensively in the literature. ${ }^{3}$ In the design of the device, the lateral wings were also modeled to simulate the effect of the device in lateral bending. The device was implanted at the L3-4 segment to study both caudal and cranial segment behavior. The intact and implanted models were loaded in all 3 main directions with the corresponding hybrid load.

In general, FE models are constructed from the CT data for a healthy human spine, which places patient-specific FE modeling out of the scope of this paper. In our study, 
those CT data came from a 35-year-old male. Injury was then simulated to create the destabilized model. Finally, the implant was inserted into the treated segment. The ROM predicted by the FE model was validated against data from published in vitro studies. ${ }^{1,4,5,7}$

Like in vitro and in vivo studies, the computational modeling techniques have certain limitations. Only one FE model of a human lumbar spine was created for this investigation. Hence, unlike in cadaveric studies, there was an inability to account for geometric variations, material changes in tissue, and anatomical variations among specimens. Other assumptions such as boundary conditions and loadings in the model may not represent real values for the human spine. Moreover, a lack of musculoskeletal structure in the model may lead to inconsistencies between FE models and real cases. A compressive follower preload was applied to the model to minimize this inconsistency.

\section{References}

1. Niosi Ca, Zhu Qa, Wilson DC, Keynan O, Wilson DR, Oxland TR: Biomechanical characterization of the threedimensional kinematic behaviour of the Dynesys dynamic stabilization system: an in vitro study. Eur Spine J 15:913922, 2006

2. Panjabi MM: Hybrid multidirectional test method to evaluate spinal adjacent-level effects. Clin Biomech 22:257-265, 2007

3. Sangiorgio SN, Sheikh H, Borkowski SL, Khoo L, Warren CR, Ebramzadeh E: Comparison of three posterior dynamic stabilization devices. Spine (Phila Pa 1976) 36:E1251E1258, 2011

4. Schilling C, Krüger S, Grupp TM, Duda GN, Blömer W, Rohlmann A: The effect of design parameters of dynamic pedicle screw systemson kinematics and load bearing: an in vitro study. Eur Spine J 20:297-307, 2011

5. Schmoelz W, Huber JF, Nydegger T, Dipl-Ing, Claes L, Wilke HJ: Dynamic stabilization of the lumbar spine and its effects on adjacent segments: an in vitro experiment. J Spinal Disord 16:418-423, 2003

6. Wilke HJ, Drumm J, Häussler K, Mack C, Steudel WI, Kettler A: Biomechanical effect of different lumbar interspinous implants on flexibility and intradiscal pressure. Eur Spine J 17:1049-1056, 2008

7. Yamamoto I, Panjabi MM, Crisco T, Oxland T: Threedimensional movements of the whole lumbar spine and lumbosacral joint. Spine (Phila Pa 1976) 14:1256-1260, 1989 